\title{
Library leadership for the digital age ${ }^{1}$
}

NFAIS Miles Conrad Memorial Lecture, February 22, 2016

\author{
Deanna B. Marcum \\ Managing Director, Ithaka S+R, 2 Rector Street, New York, NY 10065, USA \\ E-mail: deanna.marcum@ithaka.org
}

\begin{abstract}
The library profession has achieved remarkable accomplishments over my nearly-50-year career. Now we are fully into the digital environment. The leadership that is required in the digital era requires a different kind of leadership.

Keywords: Leadership, digital libraries, and digital leadership
\end{abstract}

\section{Introduction}

When I began working as a cataloging assistant at the University of Kentucky Libraries in the late 1960s, the tools I was given to work with consisted of the big Red Book of subject headings, the original blue book of Anglo-American Cataloging Rules, an electric typewriter with black/red ribbon, and an electric eraser. My job was to type the red subject heading that had been determined by the librarians onto the catalog cards. My typing skills were marginal so my electric eraser got quite a workout! These tools exemplify the extent to which the library was an end to itself. The local collection was the information resource for faculty and students, so these technology tools allowed us to represent that collection as fully as we could through entries in a card catalog.

The Internet and World Wide Web are now our tools. Through digital technology our job has changed from explicating the local collection to facilitating access to the full web of resources that are available. We can take enormous pride in the profession's embrace of technology. We have seen tremendous changes in the services that we offer and in the resources that are now available to our users. We have moved beyond simply supporting faculty research into providing support for student learning. We have grown adept at helping students make the most effective use of the many technology tools and web services that are available.

Libraries have made great strides in using technology to solve some of the most vexing problems. We can be enormously proud of what we have achieved in making more resources more accessible for many more people. Beginning with the development of OCLC, automation has been the propelling force that has given us the tools to put resources into the hands of scholars, students and the general public. We

\footnotetext{
${ }^{1}$ This paper is based upon the Miles Conrad Award Lecture that was given at the 2016 NFAIS Annual Conference in Philadelphia, PA, USA on February 22, 2016. The Miles Conrad Award was established shortly after the death of NFAIS' first President and one of the original founders, G. Miles Conrad, in order to provide a fitting memorial to his accomplishments. The award has been presented every year since 1968 to an information industry leader who has made significant contributions to the Information Community and who has been a supporter of NFAIS. A complete list of awardees can be accessed on the NFAIS website at http://www.nfais.org/miles-conrad-lectures. No slides were used during the presentation.
} 
have digitized collections and made them available to a worldwide audience. We have vastly improved library facilities that accommodate the needs of students rather than the needs of collection storage. We have become more focused on how the library helps the institution meet its goals. We have been the leaders in the digital revolution, teaching faculty and students how to use the tools that will help them be more successful. These accomplishments are laudable, and I am proud to have been part of the profession that delivered these services and products to the broader community.

And yet, there is more to do. To continue to be relevant, libraries will need to make dramatic changes, and for this to happen, leadership of a different kind is needed. I should note at the outset that I am talking primarily about executive leadership - those who are responsible for the strategic planning of their institutions, even though I believe that leadership is needed at every level of the organization.

\section{Requirements of the digital library}

All libraries are now digital. Yes, there are highly-prized and valuable special collections of print materials, and there are extraordinary artefactual audiovisual collections. I in no way diminish these collections, but when you consider what users seek from libraries, they are looking for digital resources that they can have access to from anywhere they happen to be. Users think libraries are - or at least should be - digital. And yet, we in academic libraries are still counting how many of everything we have in our local collections. We brag about how big we are or how specialized we are. We advertise our job openings with language suggesting that our size is an indicator of greatness. But as libraries become digital, the language about size or subject strength seems slightly ridiculous.

I am especially concerned about executive leadership because most of the individuals who are under consideration for these positions have at least one foot in the print world, but they are responsible for articulating the digital library's mission and vision. And most have been trained to focus on local collections, but now a national, even global mindset is key. And this different and necessary perspective requires a different kind of leadership.

\section{Different eras - Different leadership models}

Different eras have produced different forms of leadership - with different patterns of hierarchical authority, different skill sets and different views of the roles and responsibilities of institutions. In this transitional period we are now living through, we are experiencing significant changes potentially as far reaching as the transition from agricultural to industrial societies. We have moved beyond the early stages of a transition from an industrial-based society to a post-industrial, digital society, and leadership patterns, and indeed the institutions we know best, are beginning to reflect the full-blown digital era.

James McGregor Burns, the renowned management expert, and his collaborators write that the new society - variously called information society, knowledge society or networked society - is marked by four key structural changes reshaping leadership: 1) digitization of information and communications technology that is rapid and far-reaching; 2) accelerated globalization; 3) a shift toward knowledge as the central factor of production (i.e. from brawn to brains); and 4) more distributed, less hierarchical organizational forms with greatly-accelerated movement within and across organizations and sectors. In this highly dynamic environment leadership innovation and adaptability are critical, especially the leader's capacity to channel the right knowledge to the right people at the right time in the right place. ${ }^{2}$

\footnotetext{
${ }^{2}$ http://www.cidcm.umd.edu/leadership/Leadership_in_the_Digital_Age.pdf.
} 
Such changes are not confined to the business world. Libraries are also challenged in a dramatic way to deal with the demands of our users as technology allows them to gain access to information directly rather than being forced to come to us. Accelerated globalization is a factor that has been acknowledged only in the last few years, but everyone now agrees that information knows no boundaries, and that the library materials that are made available digitally are critically important to people all over the world. The rapid dissemination of information is surely a big factor in the social and economic changes we have seen taking place around the world. Education for the ordinary citizen in China or India or Africa is at least a possibility because of the information resources that libraries have made available digitally. I would characterize the "brains not brawn" factor in library terms to be our shift from processing materials to delivering services directly to our users. Instead of preparing detailed cataloging records to enter into our online catalogs, we are far more likely to invest in services that our users really want-specialized and individualized help when they can't find what they want in a Google search, access to more electronic journals and databases, on-line reference services, and access to new types of scholarly information data sets, blog posts, and multimedia resources. And in the fourth category-less hierarchical organizations, we have seen a revolution. Young librarians are not interested in several years of watching and waiting before they can make a valuable contribution. They come into library positions expecting to be part of the solution immediately. Most libraries have responded, in part to meet the demands of new professionals, and in part to the budgetary pressures they face, by flattening the hierarchy. In order to create new and exciting services for library users they are pairing the young, technically-savvy librarians who know so much more about web resources with the more experienced and knowledgeable curators who are experts on the print collections. More collections are being digitized. More faculty and students are being involved in the decisions about the library's priorities.

\section{Digital library leadership}

In trying to find answers to my question about what constitutes digital leadership, I discovered a presentation called "Talent 3.0: Solving the Digital Leadership Challenge: a Global Perspective," in which management specialists Christopher Nadhern, Dana Wade, Jonathan Harper, and Grant Duncan offer ten guidelines for developing digital leaders, and I have attempted to relate those guidelines to the profession of librarianship. ${ }^{3}$

To understand the demands for digital leadership, they conducted a comprehensive study of successful digital organizations, as defined by the extent to which they met their mission and achieved profitability. They found ten surprisingly consistent practices among these digital leaders, and for purposes of making the case for digital leadership in libraries; I am applying their ten descriptors of successful digital organizations to academic libraries. So what are these successful digital organizations doing?

\subsection{Building a comprehensive digital strategy that can be shared broadly and repeatedly across the organization}

This may be one of the greatest challenges for libraries. While a great many librarians understand that libraries for all practical purposes are digital, there are still a number of librarians who believe that digital activities are in addition to the core. We are no longer waiting for the digital revolution

\footnotetext{
${ }^{3}$ http://www.slideshare.net/oscarmirandalahoz/pagetalent-30-solving-the-digital-leadership-challenge-a-globalperspectives.
} 
to happen. It is here. Print collections continue to have great scholarly value, but students are seeking digital information - when they want it, on any device, from anywhere. At an international conference in Italy a few years ago, a librarian from the University of Ghent made this astounding statement: "I am a humble librarian; I became humble when I saw what Google could do."4 And very simply, what Google has done is make information easily accessible. The local library is no longer a collection, but a set of services that connects the user to all information everywhere.

\subsection{Embedding digital literacy across the organization}

One of the primary reasons that most of the staff consider digital librarianship to be a nice add-on is that they are not yet entirely fluent in digital librarianship. For curators and subject specialists, this means knowing as much about the digital resources as they know about print books and journals. It means knowing which web sites contain rich and authentic scholarly information. It means knowing how scholars are using blog sites and web sites to convey important research findings. It means knowing the products and services that you in this room (i.e., publishers, database producers, software and system developers, etc.) are already providing. Understanding where the digital resources can be found is in and of itself insufficient. Librarians need to know how to identify, acquire, and preserve these digital resources. It is more complicated than acquiring and storing books in the collections. Often digital acquisitions require complex intellectual property rights negotiations. Adding these materials to the library's collections will require technical know-how and a technical infrastructure that is robust enough to support digital storage and preservation. While in the print world it was possible for a few large research libraries to bear the burden of preservation, ensuring that at least a few copies of the print record would always be available, we have no such system for digital preservation. What is created in digital form must be preserved by the creators. Portico and LOCKSS are services that have been developed for the preservation of electronic journals and e-books, but there are still vast amounts of digital scholarship that are not being preserved. Digital literacy will ensure that librarians understand enough about digital creation to preserve it.

\subsection{Renewing focus on business fundamentals}

In the print world, librarians have been concerned about cataloging books and journals so that their faculty and students could discover the resources in the library. In the digital environment, our users are more likely to find digital resources through a Google search than they are through searching the library's catalog. Access to information resources is what users care about. They do not care about what the library owns. By fully integrating digital with legacy resources, we are building the kind of library that contemporary users need - and at the same time we are giving currency to our traditional mission. The role of the library changes in the digital world, and we must be honest about those changes. Students use the library as much or more than ever, but they most often use it remotely. Libraries' budgets for electronic resources have increased dramatically in recent years, but few librarians have truly analyzed in a rigorous way what this remote access means in terms of staffing, space, or organizational structure. In a digital environment, we must redefine the value proposition of libraries.

\footnotetext{
${ }^{4}$ http://libraries.casalini.it/retreat/2014_docs/2014_Van_Peteghem.pdf.
} 


\subsection{Embracing the new rules of customer engagement}

Our users, or customers, are in control. Instead of settling for what we have to offer, they can now readily determine who else can meet their information needs. Some information resources are freelyavailable through the Internet; some sources provide information for a fee. The user can decide what is most important to him or her, and also decide how much that service is worth. Libraries must be ready to listen to what the users' needs are. We are not in a position to dictate what they should want. In the web environment many user queries can be answered instantaneously. If libraries are to provide value to their users, they must be prepared to function in the Web world.

In a very real sense, libraries have become a community center - a place where users can bring their laptops or iPads and sit in the presence of their friends and fellow students, have their coffee, and do their academic work. Many libraries have taken on some aspects of cultural institutions, providing lecture series, music concerts, poetry readings and exhibits within their space, as further recognition of the need for the library to meet the broad needs of their constituents. The very meaning of the word library has changed in the digital environment. As more libraries focus on what it is they must do to help their parent organizations achieve their missions, the services will begin to look very different.

\subsection{Understanding global differences in how people access and use the Internet}

The most effective commercial organizations prioritize geographic opportunities when carrying out digital initiatives and building teams, and develop local programs to account for differences in culture, competition, and lifestyle needs. In the library world, we are not selling goods and services, but we are providing services to a widely-diverse population. Are we tailoring our services to different cultural communities? As more academic libraries understand that they play a key role in the university's or college's plans for student recruitment and retention, they must be aware of the wide array of diversity issues and facilitate access for all.

\subsection{Developing the organization's analytical skills}

Data is becoming the currency of success in a technology-driven world. Commercial organizations will be able to extract and apply insights from data to stake out a distinctive market strategy, find the best customers and charge them the right price, provide exceptional customer service, and create relevant marketing programs that drive customer behavior. Our challenge is different. Instead of relying on past practices, the digital leader will rely increasingly on data-driven decisions. What do we know about our users' interests and preferences? Are we designing our services based on that knowledge?

Libraries have placed a strong emphasis on confidentiality for their users, but without violating privacy concerns, we need to use data analytics to understand user behavior and to design services to meet their needs.

\subsection{Focusing on the customer experience}

What would libraries look like if we designed them from the user's perspective? The first thing we would realize is that with our diverse community of users, there is no one-size-fits-all service that works well for everyone. When we begin to customize services, we quickly bump into the need to have deep subject expertise instead of general librarians. We need to have librarians who partner with departments to design services that support their teaching and research missions. We need to develop student services 
that are available on phones and tablets and so easy to use that they are almost invisible. In addition, academic libraries might change their hours to better align with the Circadian rhythms of students.

\subsection{Developing leaders with skill sets that bridge traditional and digital expertise}

Experienced senior executives who did not grow up in a digital world must be willing to invest the time to learn about digital technologies and the opportunities they present. We are living in a transitional world, and the effective digital library leader will be able to bridge the print and digital worlds and help staff on both sides of the divide see the value that the other brings. The new staff will come into the organization expecting it to be digital. They will be impatient with the old rules. Digital leaders will help the more experienced staff move into the digital world with confidence and enthusiasm.

\subsection{Paying close attention to cultural fit when recruiting digital leaders}

Organizational cultures that promote innovation and collaboration, minimize functional silos, and focus on the customer are more likely to thrive in a digital world. Libraries are compelled to find and empower leaders who can advance digital objectives, given the pace, values, intensity, structure, decisionmaking process and role of digital in our libraries. Effective leaders are willing to jolt an entrenched culture when necessary. The jolt should be inspirational rather than threatening, but digital leaders must ensure that the institutions that are charged with making information resources available do so in the most up-to-date and effective way. The digital leader will help all staff see the value of offering digital services and help staff acquire the skills they need to navigate in the new world.

\subsection{Understanding the motivations of top talent}

The simple reality is that the best digital talent is still in short supply and in high demand. Libraries need to cultivate these talented staff and make it attractive for them to stay with the organization. To do this, there needs to be a clear digital strategy for the library's development, but most of all there must be an entrepreneurial culture that values experimentation and creativity; and a reporting structure that empowers leaders with digital skills. Too often, we confuse seniority with leadership. We cannot expect the younger generation of up-and-coming leaders to be interested in an organization that expects everyone to learn how the elders did it. We are in a new environment that calls for new thinking and experimentation with new processes and procedures.

\section{Conclusion}

Digital leaders are distinguished from non-leaders by their different combinations of skills, attitudes, knowledge, and their professional and personal experiences. Leadership must be driven by unique attitudes appropriate for the distributed, digital age. Digital leaders must be flexible and adaptable, and possess wide intellectual curiosity and a hunger for new knowledge. They must be willing to see value in sharply different perspectives, and be comfortable with uncertainty, and like all leaders of all times, must possess true passion for what they do. They look globally for solutions and challenges, and also hunger for constant learning. They maintain a more egalitarian and results- oriented approach than the leaders who came before them. 
The reason we need to concern ourselves with defining digital leadership is that libraries are in a pivotal moment, and a digital mindset is needed at every level of the organization. The utilization of digital technology in making research and teaching and learning easier and more efficient for those they serve is critical. Libraries' very survival depends upon making the transition from being a local institution to being a node in a national and international information ecosystem. The skills needed to build a local collection are not sufficient for seeing the challenges and opportunities in a global environment.

The greatest opportunity for digital leaders is to choose the next generation of librarians who will complete the digital revolution. It is truly an exciting time in which we can realize the dreams we have had for decades to make information resources easily and abundantly accessible to students, faculty, and the general public. Digital technology has opened the doors for us, and I eagerly await the creativity of the next generation of librarians to demonstrate the power of digital technology to provide information services that improve student learning, advance research, and inspire individual growth.

\begin{abstract}
About the author
Deanna Marcum is currently the Managing Director of Ithaka $\mathrm{S}+\mathrm{R}$ where she leads the research and consulting services that assist universities and colleges, libraries, publishers, and cultural institutions as they make the transition to the digital environment. She heads a growing staff of program directors and analysts with wide-ranging expertise. From 2003 to 2011, Deanna served as associate librarian for Library Services at the Library of Congress. Prior to that (1995-2003) she was president of the Council on Library Resources and president of the Commission on Preservation and Access. She oversaw the merger of these two organizations into the Council on Library and Information Resources (CLIR) in 1997 and served as president until August 2003.

Deanna served as director of public service and collection management at the Library of Congress from 1993 to 1995. Before that she was the dean of the School of Library and Information Science at The Catholic University of America. From 1980 to 1989, she was first a program officer and then vice president of the Council on Library Resources.

Deanna holds a doctor of philosophy in American studies, a master's degree in library science, and a bachelor's degree in English. She was awarded a doctorate in humane letters by North Carolina State University in 2010, and received the Melvil Dewey Medal, the highest award conferred by the American Library Association, in June 2011. Deanna was appointed to the Japan-US Friendship Commission, which seeks "to strengthen the US-Japan relationship through educational, cultural, and intellectual exchange," in 2013.
\end{abstract}

